\title{
Functional Health Literacy and Self-Care Behaviors Among Type 2 Diabetic Patients at a University Teaching Hospital in Kigali
}

\author{
Vestine Mukanoheli ${ }^{*}$, Marie Claire Uwamahoroํㅡ, Valens Mbarushimana ${ }^{1}$, Pamela Meharry ${ }^{2}$
}

${ }^{1}$ Colllege of Medicine and Health Sciences, University of Rwanda, Kigali, Rwanda

${ }^{2}$ Department of Women's, Children's and Family Health Services, University of Ilinois, Chicago, USA

*corresponding author: VestineMukanoheli. College of Medicine and Health Sciences, University of Rwanda, Kigali, Rwanda

Email:noelvest88@gmail.com

\section{ABSTRACT}

\section{Background}

Type 2 Diabetes Mellitus (T2DM) is a significant health burden in high-income countries and emerging in subSahara African countries, including Rwanda. Prevention and treatment of T2DM are imperative and need to focus on functional health literacy and self-care practices among people with diabetes.

\section{Objective}

To determine if functional health literacy is associated with self-care behaviors among T2DM patients.

Method

This study was a descriptive cross-sectional design conducted at a University Teaching Hospital in Kigali. The sample comprised of 223 T2DM patients recruited from the university outpatient department. The questionnaire was developed from two studies. Descriptive statistics were used to analyse the data.

\section{Results}

Results indicated a low-level of functional health literacy, with a wide range of scores from $6.5 \%$ to $93.5 \%$, and a mean of 51.66 (SD 15.77). The majority of 123 (55.3\%) had inadequate functional health literacy and self-care behaviors. There was a strong association between functional health literacy and self-care behaviors $(p<0.001)$. Conclusion

The level of functional health literacy among T2DM patients needs to be increased and patients should be highly encouraged to adhere to self-care behaviors. Future research could involve an interventional study to discover the best method to educate T2DM patients.

Keywords: Type 2 diabetes mellitus; functional health literacy; self-care behaviors; patients T2DM; subSaharan Africa.

\section{BACKGROUND}

Diabetes is a chronic non-communicable disease (NCD) that affects people of all ages and geographical locations.[1] Type 2 diabetes mellitus is the most common type of diabetes, and may respond to modifying factors.[2] Due to the chronicity of diabetes, self-care behaviors (SCB) play a significant role in the management, as well as in prevention of related complications.[3] One factor related to SCB is functional health literacy (FHL), which is described as the basic health skills and knowledge people need to accomplish daily health activities.[4]

Diabetes has risen rapidly in the past few decades worldwide, especially in high and middle-income countries.[5] Globally, an estimated 442 million adults were diagnosed with diabetes in 2014, compared to 108 million in 1980.[6]In sub-Saharan Africa (SSA), diabetes is predicted to rise rapidly, increasing by $80 \%$ over 20 years and will affect 18.7 million Africans by the year 2025.[7] In Rwanda, the prevalence of diabetes is about $3.16 \%$ of the entire population, with 1,916 deaths per year.[8] Type 2 diabetes is associated with severe complications such as cardiovascular, renal, and neurological diseases.[9]

However, T2DM complications are preventable and can be delayed.[10] The primary emphasis should be based on the promotion of lifestyles and early diagnosis,[11] as studies have shown the importance of SCB in T2DM patients. $[12,13,14]$ The literature also highlights barriers towards SCB, including low FHL and lack of T2DM knowledge that renders patients unaware of the severity of T2DM complications.[15] 
Functional health literacy directly affects the ability of T2DM patients to understand the instructions on prescription drug bottles, educational brochures, appointment slips, and healthcare provider (HCP) directions.[16] These basic factors sound simple but provide vitally important information as far as SCB with T2DM is concerned. For example, the report on 'Literacy and Health in America' revealed that approximately $14 \%$ of adults with low literacy who were given directions on a printed instruction sheet could not complete simple tasks, such as determining the appropriate dose.[17] Moreover, patients with low health literacy may have difficulty acquiring knowledge and are significantly limited in the tasks of SCB.[18] Therefore, having adequate FHL leads to adherence to SCB and improves outcomes.[19] There is a growing body of literature

\section{METHODS}

\section{Design}

A descriptive cross-sectional design was used to determine the level of FHL, factors influencing FHL and SCB of T2DM patients, and relationships between FHL and SCB. The study site was the outpatient department at the University Teaching Hospital of Kigali also known as CHUK. Data collection was three days a week from January 7 to March 7, 2019.

\section{Participants and setting}

The target population was T2DM patients attending the outpatient department at CHUK. Patients who were diagnosed with T2DM, aged 18 years or above, and agreed to sign the consent form were included in the study. Patients younger than 18 years, those involved in the pilot study, or refused to sign the consent form were excluded.

\section{Sampling size and strategy}

The sample size was calculated using Yamane's formula (1967:886), and a 95\% confidence level, and $5 \%$ margin of error. Thus, 223 patients with T2DM were recruited for the study using a convenience sampling strategy of patients with T2DM waiting in the outpatient department at CHUK.

\section{Data collection instrument}

The instruments used for data collection included two valid instruments. The FHL is the Short Test of Functional Health Literacy Assessment (STOFHLA), and permission to use the tool was granted by Refat Mehzabin.[18] The SCB assessment tool is the Summary of Diabetes SelfCare Activities Measure (SDSCA), and permission to use the tool was granted by Deborah J. Toobert.[25] All the components of both tools remained the same and were not adapted. The tool had three sections: documenting the relationships between T2DM selfcare, HL, and clinical outcomes, $[15,20,21,22]$. A study conducted in Alberta, Canada,[23] found that healthcare providers (HCP) need to consider functional health literacy (FHL) when communicating self-care education and management to T2DM patients.

To date, FHL appears to be a neglected issue in Africa. The existing literature is mostly from highincome countries. However, it is an essential aspect of self-management, which is considered a vital sign' in some literature.[4] Therefore, the aim of this study was to assess the current level of FHL and SCB in the Rwandan context, and the association between FHL and SCB.

Section one comprised of demographic characteristics developed from the literature on FHL and SCB, and included age, gender, marital status, educational level, occupation, mode of transport, and time living with T2DM. An additional item is known as 'wealth 'a societal ranking of income, ranging from I (poorest people in society), to IV (wealthiest people in society), (8 items). The scores were reported in frequencies (Table 1).

Section two included the S-TOFHLA, a scale consisting of four numerical items and 36 reading comprehension items (40 items). A score of the correct answer received one point, and an incorrect answer received zero points for both numerical items and reading comprehension items. The scores were then calculated based on percentages, which ranged from 0 to $100 \%$; thus, $0-53 \%$ for inadequate FHL, $54-66 \%$ for marginal FHL, and $67-100 \%$ is for adequate $\mathrm{FHL}$ and presented in frequencies (Figure $1)$.

Section three included the SDSCA that assessed self-care activities. The SDSCA is a self-reported tool on diabetes self-management that assessed how many times in the last seven days were the following SCB activities performed: diet, exercise, blood glucose testing, foot care, and diabetes medication (15 items). These items were measured as, Yes (1 point) or, No (0 points), with a minimum of zero days and maximum of seven days (one week). The scores were then measured in means and standard deviations (SD) (Table 2).

Section four included demographic variables and comparisons with FHL and SCB, using a one-way analysis of variance (ANOVA) with means, SD, Ftest, and p-value. A backward stepwise multiple 
regression was then used to determine the predictors of SCB, with a Beta, r-squared, adjusted $\mathrm{R}, \mathrm{F}$-test, and variance (VIF). Results were presented in Table 3 and 4; respectively.

The tool was translated from English to Kinyarwanda by a professional translator, and all participants responded in Kinyarwanda. Involving 10 adults from the sampling frame was done to test for feasibility of the study. Adults in the pilot test were not included in the main study.

\section{Data collection}

The data collection occurred in the outpatient department of CHUK after permission had been obtained from the University and the hospital. Also, the investigator had discussed the study with the outpatient department manager and the best way to approach potential participants. Patients were approached while seated and waiting for medical consultation and laboratory results.

The study was explained to potential participants, including that it was voluntary, and they could withdraw at any time without adverse consequences. Participants who met the criteria and agreed to participate signed the written consent

\section{RESULTS}

The aim of this study was to assess the level of FHL and SCB among patients with T2DM in the

Table 1. Demographic Characteristics of Participants

\begin{tabular}{ll}
\hline Variables & $\mathbf{n ~ ( \% )}$ \\
\hline Age (years) & $16(7.2)$ \\
$20-35$ & $53(23.8)$ \\
$36-50$ & $110(49.3)$ \\
$51-65$ & $43(19.3)$ \\
$66-80$ & $1(0.4)$ \\
$81-95$ & \\
Gender & $126(56.5)$ \\
Female & $97(43.5)$ \\
Male & \\
Marital status & $178(79.8)$ \\
Married & $11(4.9)$ \\
Single & $30(13.5)$ \\
Widowed & $4(1.8)$ \\
Divorced & \\
Education level & $109(48.9)$ \\
Illiterate & $93(41.7)$ \\
Primary & $14(6.3)$ \\
Secondary & $7(3.1)$ \\
Tertiary &
\end{tabular}

form. The questionnaire was then explained to participants. The questionnaire was mainly selfadministered, though at times intervieweradministered when participants needed support, if they could not read or write. The participants completed the questionnaires in the outpatient department and returned the forms to the investigator on the same day of completion.

\section{Ethical considerations}

The Institutional Review Board of the University of Rwanda College of Medicine and Health Sciences and CHUK research committee approved the study. Informed consent was obtained from each participant prior to the data collection.

\section{Data analysis}

Data were analyzed using the Statistical Package for the Social Sciences (SPSS) version 23. Frequencies, percentages, means, and standard deviations (SDs) were used to summarize the demographic characteristics of participants. Independent sample t-test, and ANOVA were used to examine the relationship between demographic variables, FHL, and SCB. The backward stepwise multiple regression was used to determine the predictors of SCB. The significance level was set at $\mathrm{p}<0.05$.

outpatient department at a referral hospital in Kigali. The demographic characteristics of the 233 participants in the study are presented in Table 1.

\begin{tabular}{ll} 
Occupation & \\
Cultivator & $82(36.8)$ \\
Business & $75(33.6)$ \\
Office worker & $8(3.6)$ \\
Student & $5(2.2)$ \\
None & $53(23.8)$ \\
Variables & $\mathbf{n}(\%)$ \\
\hline Years with T2DM & \\
$<1$ & \\
$1-3$ & $40(17.9)$ \\
$4-7$ & $59(26.5)$ \\
$\geq 8$ & $64(28.7)$ \\
Ubudehe category & $60(26.9)$ \\
I & $84(37.7)$ \\
II & $99(44.4)$ \\
III & $38(17.0)$ \\
IV & $2(0.9)$ \\
Transportation & $119(53.4)$ \\
Walk & $15(6.7)$ \\
Own car & $89(39.9)$ \\
Public transport &
\end{tabular}


Table 1 shows the demographic characteristics of participants. The results revealed that the majority of $110(49.3 \%)$ were 51-65 years, female 126 $(56.5 \%)$, and married $178(79.8 \%)$. The majority were cultivators $82(36.8 \%)$, and considered illiterate 109 (48.9), or with primary level education $93(41.7 \%)$. The income variable showed that the majority were Ubudehe category II, with 99 (44.4\%), and walked to the hospital 119 (53.4\%).

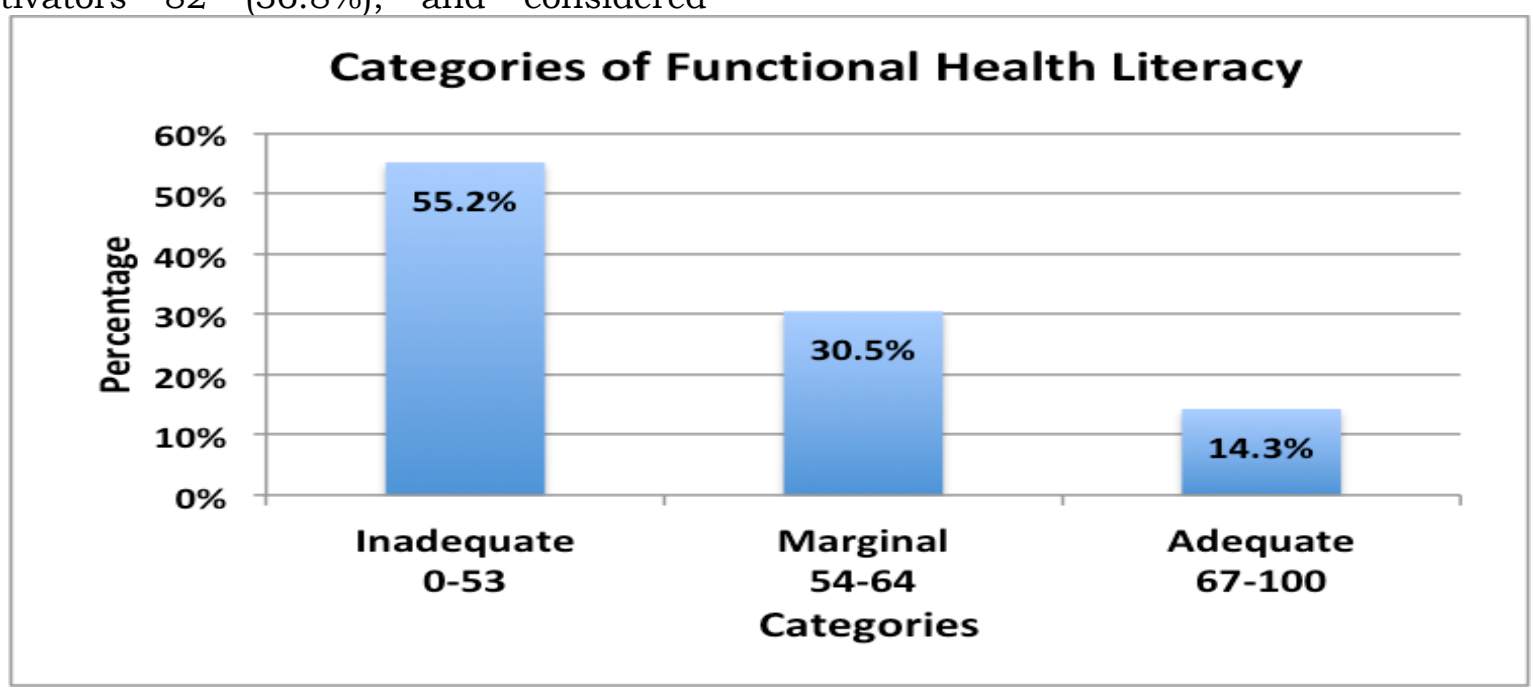

Figure 1. Functional Health Literacy Among Participants

The FHL among participants identifies the three different categories (Figure 1). The majority of 123 (55.3\%) had inadequate FHL, 68 (30.5\%) had marginal FHL, and only $32(14.3 \%)$ had adequate FHL.

Table 2. Self-Care Behaviors of Participants

\begin{tabular}{|c|c|c|c|c|}
\hline Variables & Mean & SD & $\operatorname{Max}$ & Min \\
\hline Followed a healthy eating plan & 2.01 & 1.94 & 7 & 0 \\
\hline Followed an eating plan & 2.07 & 1.94 & 7 & 0 \\
\hline Eat fruits and vegetables & 2.19 & 1.93 & 7 & 0 \\
\hline Eat high-fat foods & 2.05 & 1.78 & 7 & 0 \\
\hline At least 30 min of physical activity & 1.39 & 1.89 & 7 & 0 \\
\hline In a specific exercise session & 1.04 & 1.68 & 7 & 0 \\
\hline Test your blood sugar & 1.61 & 2.10 & 7 & 0 \\
\hline Test your blood sugar as recommended & 1.47 & 2.03 & 7 & 0 \\
\hline Check your feet & 1.74 & 2.33 & 7 & 0 \\
\hline Inspect the inside of your shoes & 1.42 & 2.18 & 7 & 0 \\
\hline Wash your feet & 6.65 & 0.72 & 7 & 0 \\
\hline Soak your feet & 2.31 & 2.88 & 7 & 0 \\
\hline Dry between your toes after washing & 2.29 & 2.75 & 7 & 0 \\
\hline Take recommended diabetes medication & 6.82 & 0.75 & 7 & 0 \\
\hline Overall self-care activities & 2.51 & 1.28 & 6.1 & 0.9 \\
\hline
\end{tabular}

Table 2 shows that the overall mean \pm SD score of performing $\mathrm{SCB}(\mathrm{M} \pm \mathrm{SD}=2.51 \pm 1.28)$. This score indicates that participants performed most SCB activities nearly three days a week, which indicates poor adherence to self-care activities. The lowest mean in performing self-care activities was from specific exercise $(\mathrm{M} \pm \mathrm{SD}=1.04 \pm 1.68)$ and the highest was attributed to taking diabetes medication $(\mathrm{M} \pm \mathrm{SD}=6.82 \pm 0.75)$. 
Rwanda Journal of Medicine and Health Sciences Vol.3 No.1, March 2020 https://dx.doi.org/10.4314/rjmhs.v3i1.7

Table 3. Demographic Characteristics and Comparisons with FHL and SCB

\begin{tabular}{|c|c|c|c|c|c|c|c|}
\hline \multirow[b]{2}{*}{ Characteristic } & \multicolumn{3}{|c|}{ Functional Health Literacy } & \multicolumn{2}{|c|}{ Self-Care Behaviors } & \multirow[b]{2}{*}{$\mathbf{F}$} & \multirow[b]{2}{*}{$\mathbf{p}$} \\
\hline & n (\%) & Mean (SD) & $\mathbf{F}$ & $\mathbf{p}$ & Mean (SD) & & \\
\hline Age (years) & & & 11.27 & 0.000 & & 35.77 & 0.000 \\
\hline $18-35$ & $16(7.2)$ & $68.3(14.6)$ & & & $3.1(1.9)$ & & \\
\hline $36-50$ & $53(23.8)$ & $55.0(17.1)$ & & & $2.9(1.7)$ & & \\
\hline $51-65$ & $110(49.3)$ & $50.4(14.6)$ & & & $2.3(0.98)$ & & \\
\hline$\geq 66$ & $44(19.7)$ & $44.6(11.9)$ & & & $2.1(0.70)$ & & \\
\hline Education & & & 35.77 & 0.000 & & 55.46 & 0.000 \\
\hline None & $109(48.9)$ & $46.6(12.8)$ & & & $2.1(0.09)$ & & \\
\hline Primary & $93(41.7)$ & $51.5(13.9)$ & & & $2.4(0.09)$ & & \\
\hline Secondary & $14(6.3)$ & $75.1(9.9)$ & & & $4.1(1.9)$ & & \\
\hline Tertiary & $7(3.1)$ & $84.7(4.0)$ & & & $6.2(0.03)$ & & \\
\hline Marital status & & & 14.85 & 0.000 & & 9.55 & 0.000 \\
\hline Married & $178(79.8)$ & $51.3(14.4)$ & & & $2.4(1.1)$ & & \\
\hline Divorced & $4(1.8)$ & $66.9(19.7)$ & & & $4.0(1.8)$ & & \\
\hline Single & 11 (4.9) & $75.0(14.9)$ & & & $4.1(1.8)$ & & \\
\hline Widowed & $30(13.5)$ & $42.7(14.0)$ & & & $2.1(1.1)$ & & \\
\hline Wealth category & & & 12.58 & 0.000 & & 24.98 & 0.000 \\
\hline Category I & $84(37.7)$ & $45.3(12.6)$ & & & $2.0(0.77)$ & & \\
\hline Category II & 99 (44.4) & $52.8(14.3)$ & & & $2.4(0.99)$ & & \\
\hline Category III & $38(17.0)$ & $62.6(19.1)$ & & & $3.8(1.83)$ & & \\
\hline Category IV & $2(0.9)$ & $45.1(4.5)$ & & & $1.5(0.30)$ & & \\
\hline Occupation & & & 24.84 & 0.000 & & 24.21 & 0.000 \\
\hline Cultivator & $82(36.8)$ & $47.8(11.5)$ & & & $2.1(0.79)$ & & \\
\hline Business & 75 (33.6) & $57.1(12.8)$ & & & $2.7(1.2)$ & & \\
\hline Office worker & $8(3.6)$ & $84.2(6.3)$ & & & $5.7(1.2)$ & & \\
\hline Student & $5(2.2)$ & $69.0(20.2)$ & & & $3.7(2.0)$ & & \\
\hline None & $53(23.8)$ & $43.1(15.7)$ & & & $2.2(1.0)$ & & \\
\hline Transport & & & 19.43 & 0.000 & & 48.76 & 0.000 \\
\hline Own car & $15(6.7)$ & $68.8(21.0)$ & & & $4.9(2.1)$ & & \\
\hline Public transport & 89 (39.9) & $55.2(14.0)$ & & & $2.6(1.1)$ & & \\
\hline Walk & 119 (53.4) & & & & & & \\
\hline
\end{tabular}


Table 3 shows the relationships between demographic characteristics, FHL, and SCB. The results indicate the significance of FHL and the participant's age, f $11.27(\mathrm{p}<0.001)$; education level, f $35.77(\mathrm{p}=0.000)$, and marital status $\mathrm{f} 14.85$ $(p=<0.001)$. The wealth category f, $12.58(p=0.000)$ demonstrated the significance of the period living with diabetes $f 3.62 \quad(p=0.0139)$. Occupation demonstrated significance with FHL, f 24.84 $(p=0.000)$, and means of transport also significant with FHL f $19.43(\mathrm{p}=0.000)$. However, gender does not show any statistical significance $(\mathrm{p}=0.479)$.

For SCB, several of the demographic characteristics had statistical association. Significant demographic variables included, age, f $35.77 \quad(p=0.000)$; educational level, f $55.46(\mathrm{p}=0.000)$; marital status, f $9.55(\mathrm{p}=0.000)$, Ubudehe category, f 24.98 $(\mathrm{p}=0.000)$, occupation, f $24.21(\mathrm{p}=0.000)$; and mode of transport, f $48.76(p=0.000)$.

Table 4. Regression Analysis of SCB, FHL, and Demographic Characteristics

\begin{tabular}{lllllll}
\hline $\begin{array}{l}\text { Variables } \\
\text { Dependent } \\
\text { (Response) }\end{array}$ & $\begin{array}{l}\text { Independent } \\
\text { (Predictors) }\end{array}$ & B & $\mathbf{r}^{\mathbf{2}}$ & $\mathbf{R}^{\mathbf{2}}$ & F p-value & VIF \\
\hline Self-Care & FHL & $0.23^{* * *}$ & 0.4083 & 0.3919 & 0.0001 & 1.00 \\
Behaviors & Age & $0.20^{* * *}$ & & & & \\
& Education & $0.03^{* * *}$ & 0.1053 & & & \\
& Wealth category & $0.18^{*}$ & & 0.231 & 0.001 & \\
& Marital status & $0.12^{*}$ & & & & \\
& Occupation & $0.11^{* *}$ & & & & \\
& Transport & $0.04^{*}$ & & & &
\end{tabular}

B: Beta; r $^{2}$ : r-squared; R $^{2}$ : Adjusted R $\mathrm{R}^{2} ; \mathrm{F}$ : F-test; VIF: Variation inflation factor

${ }^{*}$ p-value $<.05,{ }^{* *}$ p-value $<.01,{ }^{* * *}$ p-value $<.001$.

Table 4 shows the associations of SCB, FHL, and demographics characteristics 


\section{DISCUSSION}

This is the first study to measure FHL and SCB among patients with T2DM at CHUK in Rwanda using the S-TOFHLA and SDSCA valid instruments. We found a low level of FHL, and poor performance of SCB among participants. Furthermore, FHL was associated with SCB in this study population.

\section{Demographic Characteristics of Participants}

The results show that the majority was female $(56.5 \%)$ and married $(79.8 \%)$ who attended the outpatient department for a T2DM consultation at CHUK (Table 1). These findings are similar to a US Primary Care Setting that show the majority of Somali patients who suffered from T2DM were female and married.[27]Most participants did not attend formal school (48.1\%), which is in contrast to the highly educated participants in a populationbased cohort study [28] that observed a significant association between the lowest educated individuals and T2DM incidence. Steele's findings were likely due to their study objective, which was to assess the factors between educational attainment and incidence of T2DM in older adults.[28]

Interestingly, the participant's occupation revealed some surprising data. For years, T2DM has been known as a disease of rich people and attendant professions, rather than farmers. However, in the present study, the majority were cultivators (36.8\%), and the minority worked in business. This finding may reflect that the majority of workers in Rwanda are cultivators, and few are immune to the burden of T2DM, irrespective of location and profession.

\section{Level of functional health literacy}

Functional health literacy is the basic knowledge and skills that patients may use to make the right decision for themselves.[16] The tool, used to evaluate the FHL was the S-TOFHLA, and results revealed that over half $(57.7 \%)$ had inadequate FHL, nearly a third $(30.5 \%)$ had marginal FHL, and only a limited proportion $(16.7 \%)$ had adequate FHL (Figure 1). The alarming results reveal that the majority of patients attending the outpatient department at CHUK on the days that we surveyed have a low HL level. Similar results were found in a study in Portugal,[29] which was likely due to a similar methodology, including the public health site. Other studies show low levels of HL, $[16,27]$ including one conducted in Ethiopia on knowledge, SCB, and adherence to medications.[30]

The results of these studies are in contrast to a study conducted in private clinics in the Marshall Islands, [24] which showed that patients with T2DM have adequate FHL level. The HCPs working in private clinics are more likely to educate their patients, compared to public health facilities. Patients with T2DM need to acquire and understand the information necessary to use basic health skills and accomplish daily health activities. Therefore, health literacy is essential to know and practice SCB, and it is recommended that HCPs help patients attain adequate $\mathrm{FH}$ literacy.

\section{Self-care behaviors}

In this study, the SCB were evaluated using the SDSCA measure developed by Toobert.[25] It is a brief self-report questionnaire of diabetes selfmanagement that includes items assessing the following aspects: diabetes diet, specific diet, exercise, foot care, blood glucose testing, and medications. The data presented in Table 3 shows that during the previous seven days, the participants only followed the overall self-care activities about two and half days a week $(\mathrm{M} \pm \mathrm{SD}=2.51 \pm 1.28)$. This finding indicates the poor performance of SCB among participants in general, and similar to results reported by Protheroe,[19] who reported the poor performance of SC activities.

\section{Diet}

Participants reported poor adherence to SC activity in the diet. During the previous seven days, they only followed the healthful eating plan, and fruits and vegetables twice a week $(\mathrm{M} \pm \mathrm{SD}=2.01 \pm 1.94)$ and $(\mathrm{M} \pm \mathrm{SD}=2.19 \pm 1.93)$, respectively. Fresh fruit and vegetables are essential for the diet of a patient with T2DM. Vegetables play a remarkable role in human nutrition and health due to the high content of dietary fiber, phytochemicals, vitamins, and minerals.[33] Health care providers should emphasize the importance of fresh fruit and vegetables in the diet, which may help in disease management, appropriate self-care, and better quality of life.

During the previous seven days, participants consumed high-fat foods about twice a week, with a mean of $2.05(\mathrm{SD}=1.78)$. The literature revealed the impact of consuming fatty food as it can lead to severe cardiovascular diseases.[33]

\section{Physical activity}

Results of the two physical activity questions show that participants had 30 minutes of physical activity one day a week $(\mathrm{M} \pm \mathrm{SD}=1.39 \pm 1.89)$, and a specific exercise session $(\mathrm{M} \pm \mathrm{SD}=1.04 \pm 1.68)$. The results indicated that patients' adherence to physical activities was low, yet physical activities have a high impact on the management of T2DM.The association between physical activity (PA), sedentary life, and incident diabetes has been assessed in a variety of populations.[34] Our results 
are in line with a study in south western Ethiopia by Kassahun,[30] which revealed poor adherence to the physical activities among adults with T2DM. However, our results on physical activity should be interpreted with caution as the majority were aged 51-65 years, and many walk to places, as it is their only primary means of transportation.

\section{Foot care}

There were five questions on SCB and foot care. The results indicate that participants washed their feet nearly every day of the week $(\mathrm{M} \pm \mathrm{SD}=6.65 \pm 0.72)$; and soaked their feet, and dried between their toes over twice a week, $(\mathrm{M} \pm \mathrm{SD}=2.31 \pm 2.88), \quad$ and $(\mathrm{M} \pm \mathrm{SD}=2.29 \pm 2.75), \quad$ respectively. However, inspecting their feet $(\mathrm{M} \pm \mathrm{SD}=1.74 \pm 2.33)$, and inspecting the inside of shoes, $(\mathrm{M} \pm \mathrm{SD}=1.42 \pm 2.18)$, was less than two times a week.

\section{Blood glucose}

Results of the two questions on self-monitoring of blood sugar revealed that participants only checked blood sugar one or two times a week $(\mathrm{M} \pm \mathrm{SD}=1.6 \pm 2.10)$. Also, participants only checked their blood sugar 'as recommended' even less $(\mathrm{M} \pm \mathrm{SD}=1.47 \pm 2.03)$. Testing of blood glucose is considered the cornerstone in the management and prevention of serious complications.[6] Type 2 diabetes mellitus is a chronic disease, which requires the maintenance of blood glucose in the normal range to prevent the aggravation and severe complications related to hyperglycemia such as heart disease, stroke, renal failure, and blindness.

Our results are similar to other studies. A population-based study in Denmark reported that testing of blood glucose was generally poor, which is surprising considering Denmark is a high-income country, as healthcare is covered by high taxes. This finding is in contrast with another study in Bali that had low SMBG, which is usually associated with low-income countries.[35] The same results were obtained in another study,[19] which demonstrated poor adherence among participants with a negative impact on the blood glucose level and diabetes outcome. There is a need to increase education to T2DM patients on the importance of controlled blood glucose. Furthermore, patients should be supported to afford glucometers and strip reagents.

\section{Medication}

There was one question on SCB and adherence to medications. The result indicates that participants take the recommended diabetes medication nearly every day of the week $(\mathrm{M} \pm \mathrm{SD}=6.82 \pm 0.75)$, similar to another study in Marshall Islands.[24] The reason may be due to the similar sample size of and study design. Medication is vital in SCB outcome, [30] as a significant number of participants were adhering to medication, and only a few did not.
As T2DM is a chronic disease requiring long-term self-care management adherence to medication is required to reduce the risk of complications.[31] Health care providers take care of their patients not only by giving drugs, but also by teaching and encouraging patients to practice SCB.[32] Continuous education should be encouraged to promote medication adherence.

The overall SCB in this study was revealed to be low and can negatively impact the type 2 . Studies should be conducted in our context to find out strategies that can help patients with T2DM to perform SCB.

\section{Relationship between FHL and SCB among T2DM participants}

The results of this study showed a strong relationship between FHL and SCB among T2DM patients (p-value <0.001) (Table 3). The following demographic variables all showed statistical association with FHL and SCB and included age, education, marital status, Ubudehe category, occupation, and mode of transport.

In relation to education, participants with no formal education and tertiary education had $(\mathrm{M} \pm \mathrm{SD}=46.6 \pm 12.8), \quad$ and $(\mathrm{M} \pm \mathrm{SD}=84.7 \pm 4.0)$, respectively, indicating a significant level of FHL is associated with higher education $(p<0.000)$. There corresponding results showed SC activities for participants with no formal education $(\mathrm{M} \pm \mathrm{SD}=2.1 \pm 0.09)$, and tertiary education $(\mathrm{M} \pm \mathrm{SD}=6.2 \pm 0.03)$, which also showed a strong association $(\mathrm{p}<0.000)$. A similar result was found in a study conducted in Southwestern Ethiopia.[14] Marital status is also associated with FHL and SCB, as single participants had a high level of FHL compared to married participants.

Our results were similar to other studies.[3,15,33] Patients with SCB, coupled with FHL, are more likely to have better T2DM outcomes.[19] Patients with adequate FHL may feel more comfortable in performing SCB and therefore may have better diabetes outcomes.[15] In contrast, other studies $[21,36]$ indicated there is limited evidence to link HL with outcomes of T2DM care. Therefore, assessing whether inadequate $\mathrm{HL}$ is associated with patients' SMBG is an important area to explore further,[16] and in different settings.

\section{Factors associated with FHL and SCB among T2DM participants}

Stats from Table 4 Our results show that SCB is affected by FHL, as there was an association between FHL and SCB, as presented in Table 4. Age was a factor to FHL and SCB, as age increases the FHL and SCB decrease. 
Similar results are found in studies conducted in other areas like a public diabetes clinic on Majuro Atoll, the Marshall Islands and in Switzerland . $[24,37]$ The level of education affects the FHL and $\mathrm{SCB}$, as participants with a higher level of education had better FHL scores and good SCB, similar to another study.[38] Gender does not affect FHL and SCB, similar to findings in National Health Interview Survey US.[38]

\section{CONCLUSION}

This study aimed to assess the relationship between FHL and SCB. Findings from our study population indicate the FHL level was inadequate, and SCB was poor. A strong relationship between FHL and SCB was associated with age, gender, marital status, educational level, period living with diabetes, and means of transport. The emphasis should be placed on identifying all factors related to SCB, and implementation of strategies that affect change and adherence. Self-care is the key to the management of T2DM, and patients have a vital role in the success of diabetes care and the outcome. There is a need to incorporate FHL evaluation in the care of T2DM patients, and continuing education and regular SCB assessments is crucial. A future study should include more sites and an intervention to increase adherence to SCB.

\section{Acknowledgements}

The researchers acknowledge all T2DM patients who agreed to participate in this study

This article is published open access under the Creative Commons AttributionNonCommercialNoDerivatives (CC BYNC-ND4.0). People can copy and redistribute the article only for noncommercial purposes and as long as they give appropriate credit to the authors. They cannot distribute any modified material obtained by remixing, transforming or building upon this article. See https://creativecommons.org/licenses/by-ncnd $/ 4.0 /$

\section{REFERENCES}

1. Sami W, Ansari T, Butt NS, Rashid M, Hamid A. Effect of diet on type 2 diabetes mellitus: A review. 2017;11(2):12-5.

2. Al-Hussaini M. Adolescents' knowledge and awareness of diabetes mellitus in Kuwait. Alexandria J Med [Internet]. 2016;52(1):61-6. Available from: http://dx.doi.org/10.1016/j.ajme.2015.04.0
01

3. Zuercher E, Diatta ID, Burnand B. Health literacy and quality of care of patients with diabetes : A cross-sectional analysis. 2017;18.

4. Bailey SC, Brega AG, Crutchfield TM, Elasy $\mathrm{T}$, Herr $\mathrm{H}$, Kaphingst $\mathrm{K}$, et al. Update on health literacy and diabetes. Diabetes Educ. 2014;40(5):581-604.

5. Blanks SH, Treadwell H, Bazzell A, Graves W, Osaji O, Dean J, et al. Community engaged lifestyle modification research: engaging diabetic and prediabetic African American women in community-based interventions. J Obes. 2016;2016:5-7.

6. Friis K, Vind BD, Simmons RK, Maindal HT. The relationship between health literacy and health behaviour in people with diabetes: a Danish population-based study. 2016;2016.

7. Chan HTH, Health P. Diabetes and clinical research diabetes in rural Rwanda: high retention and positive outcomes after 24 months of follow-up in the setting of chronic care integration. ClinMed. 2016;3(2).

8. Ministry of Health. Republic Of Rwanda. Noncommunicable. 2015;(November):20.

9. Tapela N, Habineza H, Anoke S, Harerimana E, Mutabazi F, Hedt-Gauthier B, et al. Diabetes in rural Rwanda: high retention and positive outcomes after 24 months of followup in the setting of chronic care integration. Int J Diabetes Clin Res. 2016;3(2).

10. Lindström J. Prevention of Type 2 diabetes with lifestyle Intervention - Emphasis on dietary composition and identification of high-risk individuals. 2016.

11. Yee LM, Niznik CM, Simon MA. Examining the role of health literacy in optimizing the care of pregnant women with diabetes. 2016;1(212):1242-9.

12. Camaraa A, Balde NM, Kengn JS-TAP, Diallo MM, Kake APKTA, Sylvie N, et al. Poor glycemic control in type 2 diabetes in the South of the Sahara: The issue of limited access to an HbA1c test. Diabetes Res Clin Pract J. 2015;108:187-92.

13. Kirk JK, Stegner J. Self-monitoring of blood glucose: practical aspects. J Diabetes Sci Technol. 2010;4(2):435-9. 
14. Kassahun T, Gesesew H, Mwanri L, Eshetie T. Diabetes related knowledge, self-care behaviours and adherence to medications among diabetic patients in Southwest Ethiopia: A cross-sectional survey. BMC Endocr Disord [Internet]. 2016;16(1):1. Available from: http: / /dx.doi.org/ 10.1186/s12902-0160114-x

15. Reisi M, Mostafavi F, Javadzade H, Mahaki B, Tavassoli E, Sharifirad G. Impact of health literacy, self-efficacy, and outcome expectations on adherence to self-care behaviors in Iranians with type 2 diabetes. Oman Med J. 2016;31(1):52.

16. Moss TR. The impact of health literacy on clinical outcomes for adults with Type 2 diabetes mellitus. Adv Diabetes Metab. 2014;2(1): 14 .

17. Ezebuihe I, Sigley C. Health Literacy: Concept. Int $\mathrm{J}$ Healthc Sci ISSN. 2017;4(2):55-62.

18. Refat Mehzabi M, Hossain KJ, Sayeed SKJB. Association of Functional Health Literacy with Glycemic Control: 1: A cross-sectional study in urban population of Bangladesh. 2019;(April).

19. Protheroe J, Rowlands G, Bartlam B, LevinZamir D. Health literacy, diabetes prevention, and self-management. 2017;2017:10-3.

20. Schillinger D, Grumbach K, Piette J, Wang F, Osmond D, Daher C, et al. With Diabetes Outcomes. Prim Care. 2002;288(4):475-82.

21. Bains SS, Egede LE. Associations between health literacy, diabetes knowledge, self-care behaviors, and glycemic control in a lowincome population with type 2 diabetes. Diabetes Technol Ther. 2011;13(3):335-41.

22. van der Heide I, Uiters E, Rademakers J, Struijs JN, Schuit AJ, Baan CA. Associations among health literacy, diabetes knowledge, and self-management behavior in adults with diabetes: results of a Dutch cross-sectional study. J Health Commun. 2014;19 Suppl 2(October): 115-31.

23. Sayah F Al, Williams B, Pederson JL, Majumdar SR, Johnson J a. Health literacy and nurses' communication with Type 2 diabetes patients in primary care settings. Nurs Res. 2014;63(6):408-17.
24. Bohanny W, Lecturer RN, Wu SV, Associate RN. Health literacy, self-efficacy, and selfcare behaviors in patients with type 2 diabetes mellitus. Am Assoc Nurse Pract. 2013;25(9 September):495-502.

25. Toobert DJ, Hampson SE, Glasgow RE. The summary of diabetes self-care. Diabetes Care J. 2000;23(7):943-50.

26. Johnston. Self-Efficacy Impacts self-care and HBA1C in young adults with Type i diabetes. 2002;51:43-51.

27. Njeru JW, Hagi-salaad MF, Haji H, Cha SS, Wieland ML. Diabetes health literacy among somali patients with diabetes mellitus in a US primary care setting. 2015;

28. Steele CJ, Schöttker B, Marshall AH, Kouvonen A, O'Doherty MG, Mons U, et al. Education achievement and type 2 diabetes What mediates the relationship in older adults? Data from the ESTHER study: A population-based cohort study. BMJ Open. 2017;7(4):1-10.

29. Liliana Abreu JA. Distributed health literacy among people living with type 2 diabetes in Portugal: Defining levels of awareness and support. 2017;(May):2.

30. Kassahun T, Gesesew H, Mwanri L, Eshetie T. Diabetes related knowledge, self-care behaviours and adherence to medications among diabetic patients in Southwest Ethiopia: a cross-sectional survey. BMC Endocr Disord [Internet]. 2016;1-10. Available from: http: / /dx.doi.org/ 10.1186/s12902-0160114-x

31. Lopez JMS, Katic BJ, Fitz-randolph M, Jackson RA, Chow W, Mullins CD. Understanding preferences for type 2 diabetes mellitus self-management support through a patient-centered approach: a 2phase mixed-methods study. BMC Endocr Disord [Internet]. 2016;1-11. Available from: http: / /dx.doi.org/ 10.1186/s12902-0160122-x

32. Der Ovan. Functional, communicative and critical health literacy of chronic disease patients and their importance for selfmanagement. 2015;98(1):41-8.

33. Çaylan A, Yayla K, Öztora S, Dağdeviren HN. 
Rwanda Journal of Medicine and Health Sciences Vol.3 No.1, March 2020 https://dx.doi.org/10.4314/rjmhs.v3i1.7

Assessing health literacy, the factors affecting it and their relation to some health behaviors among adults. 2017;28(15):6803-7.

34. Joseph JJ, Echouffo-Tcheugui JB, Golden SH, Chen H, Jenny NS, Carnethon MR, et al. Physical activity, sedentary behaviors and the incidence of type 2 diabetes mellitus: The multi-ethnic study of atherosclerosis (MESA). BMJ Open Diabetes Res Care. 2016;4(1).

35. Putra Yasa DPG, Rahayu VES, Widastra IM, Labir IK, Wedri NM, Sulisnadewi NLK. Barrier of self care management on urban Type 2 diabetic patients in Bali. Indian J Public Heal Res Dev. 2018;9(5).
36. Al Sayah F, Majumdar SR, Williams B, Robertson S, Johnson JA. Health literacy and health outcomes in diabetes: A systematic review. J Gen Intern Med. 2013;28(3):44452.

37. Flatz A, Casillas A, Stringhini S, Zuercher E, Burnand B, Peytremann-Bridevaux I. Association between education and quality of diabetes care in Switzerland. Int $\mathrm{J}$ Gen Med. 2015;8:87.

38. Yang NH, Lee Y, Ha M. Effects of health literacy and knowledge on diabetic self-care in the elderly with DM living alone. 2016;27(4):370-9. 